\title{
PARQUE DA CIDADE MÃE BONIFÁCIA, CUIABÁ-MT: TOPOFILIA E AMENIZAÇÃO CLIMÁTICA EM UM FRAGMENTO DE CERRADO URBANO
}

\author{
Marcelo Paes de Barros ${ }^{1}$, Carlo Ralph de Musis ${ }^{2}$, Carmen Hornick ${ }^{3}$ \\ (recebido em 03.03.2010 e aceito para publicação em 10.06.2010)
}

\section{RESUMO}

O trabalho teve por objetivo realizar uma análise para identificar o sentimento topofílico que os visitantes têm em relação ao Parque Mãe Bonifácia, em Cuiabá, MT em paralelo a uma análise microclimática do espaço. O estudo topofílico foi realizado através da aplicação de questionários com os visitantes com objetivo de avaliar a percepção destes em relação ao Parque, enquanto que o estudo microclimático foi desenvolvido através da coleta de dados de temperatura e umidade relativa do ar em pontos internos e em um ponto externo ao espaço. Associada à análise microclimática, que apresentou o lugar como uma ilha de frescor para a região, a análise da percepção pode inferir que a população dos visitantes identifica-se e sente-se envolvida pelas diferentes sensações produzidas pelo ambiente do Parque Mãe Bonifácia. Isto indica um grau acentuado de topofilia para com o mesmo, refletindo em atitudes de respeito e conservação do espaço, o que torna possível o desenvolvimento de programas de Educação Ambiental. Os resultados da pesquisa podem fornecer subsídios a projetos de construção de outros parques ou revitalização de áreas verdes em regiões com características climáticas semelhantes.

Palavras-chave: Percepção ambiental, áreas verdes urbanas, ilha de frescor.

\footnotetext{
1. Físico e Engenheiro Civil, Doutorando em Física Ambiental pela Universidade Federal de Mato Grosso, docente do Instituto de Física da Universidade Federal de Mato Grosso, Cuiabá, MT, mpb9@terra.com.br;

${ }^{2}$ Engenheiro Civil, Doutor em Educação pela Pontifícia Universidade Católica de São Paulo, docente da Universidade de Cuiabá e do Programa de Estudos Pós-Graduados em Física Ambiental da Universidade Federal de Mato Grosso, Cuiabá, MT, carlo.ralph@iuni.com.br;

3 Graduada em Letras Português Inglês, Mestrado em Estudos de Linguagem pela Universidade Federal de Mato Grosso, docente da Universidade de Cuiabá, Cuiabá, MT, carmen_hornick@hotmail.com.
} 


\title{
MÃE BONIFÁCIA CITY PARK, CUIABÁ-MT: TOPOPHILIA AND CLIMATIC MITIGATION IN URBAN CERRADO FRAGMENT
}

\begin{abstract}
The aim of this study is to develop an analysis in order to identify the topophilic feeling that its visitors have concerned of Mãe Bonifácia Park, in Cuiabá, MT, in parallel a microclimatic analysis to the place. The topophilia profile was investigated through a survey answered by the visitors with the objective of assessing their perception of the park, while the microclimatic study was developed by collecting information about the air temperature and humidity in internal and external points. Associating the microclimatic analysis that presented the place as a fresh island for the region, to the perception analysis, it is possible to infer that the visitors enjoy and feel involved with Mãe Bonifácia Park environment. This indicates a high topophilia level, causing respect and conservation attitudes to the area, what make possible a green awareness program development. The results of this study can be useful to new projects development or green urban areas revitalization with similar features.
\end{abstract}

Keywords: environmental perception, green urban areas, fresh areas. 


\section{INTRODUÇÃO}

O escritor lusitano José Saramago, na sua obra "Ensaio Sobre a Cegueira", descreve o que ocorreria caso houvesse uma epidemia que fizesse as pessoas, de súbito, perder a visão. Ao fim da saga de alguns "cegos" atingidos pela epidemia, o autor comenta sobre a responsabilidade daqueles que possuem olhos quando os outros os perderam, chegando à conclusão de que "nem todos os casos são iguais, e o tempo não tem feito outra coisa que dizer-nos que não há cegos, mas cegueiras" (SARAMAGO, 1995, p. 147).

As referidas cegueiras nada mais são que formas diferentes de perceber uma mesma realidade. A percepção a respeito de um ambiente varia enormemente entre pessoas de culturas ou idades diferentes. Tuan (1980, p. 4) define percepção como "a resposta dos sentidos aos estímulos externos, atividade proposital na qual certos fenômenos são claramente registrados enquanto outros são bloqueados".

Assim, uma pessoa ao percorrer e experimentar um determinado espaço atribui um valor a este, determinando uma relação de percepção nada passiva, que pode evoluir para um sentimento onde o espaço, diferenciado, torna-se um lugar (SANTOS, 2005). estabelecimento de uma teia de relações entre o homem e o seu ambiente próximo vai além do que se imagina, coexistindo uma relação íntima entre os mesmos.

Para expressar esse relacionamento Yi Fu Tuan criou o termo topofilia, que significa para ele: "O elo afetivo entre a pessoa e o ambiente físico. Difuso como conceito e concreto como experiência" (TUAN, 1980, p. 5). O conceito de topofilia está associado à valorização do lugar por meio de um sentido não mediado, o gosto.

A topofilia assume muitas formas e varia muito em amplitude emocional e intensidade, tendo seu conteúdo baseado nas características físicas do lugar. A resposta pode ser estética, causada pela sensação de beleza fornecida pela vista de uma paisagem, ou pode ser táctil, pelo prazer do contato físico com o ar, a água ou a terra.

Com relação às paisagens urbanas, a atração do homem ocorre pelos contrastes existentes nestes espaços, oposições como o público e o privado ou luz e escuridão. No caso das paisagens naturais, mesmo quando estas dominam o homem, "a apresentação delicada de seus atributos físicos indica uma sensibilidade para as qualidades estéticas do ambiente despertando a afeição do homem pelo mesmo" (TUAN, 1980, p 193). Quando as paisagens são áreas verdes que constituem um espaço inserido no sistema urbano, sejam fragmentos dos espaços naturais da região ou ambientes construídos pelo homem, a contraposição entre os atributos de cada estrutura da paisagem tende a evocar, de maneira 
ainda mais intensa, os sentimentos topofílicos para com o lugar, despertando sensações de aventura, luz e liberdade.

Porém, mais que apenas um fator psicológico, Mendonça (2003, p. 56), analisando estudos relativos ao clima urbano elaborados até o presente, encontrou repetidos relatos sobre a "importância dos espaços verdes dentro das áreas urbanas, notadamente como reguladores das amplitudes termo-higrométricas geradoras de desconforto térmico". A World Health Organization e United Nations Environment Programme (WHO/UNEP, 1990) nega a idéia da existência de um índice ou uma zona de conforto térmico mundial, no entanto, Weihe (1986), em estudo sobe a expectativa de vida nos climas tropicais em função da urbanização, estabelece uma larga faixa de neutralidade térmica aceitável, sem impacto à saúde, entre $17^{\circ} \mathrm{C}$ e $31^{\circ} \mathrm{C}$.

Relacionando os fatores físicos e psicológicos, Corbella (2003) destaca que a simples presença de arborização numa região faz com que as zonas de conforto térmico possam ser bastante alargadas na região da temperatura máxima, com relação à normalmente referida nos livros provindos de países frios.

Na cidade de Cuiabá, MT, que apresenta temperaturas elevadas ao longo de todo o ano, a percepção de conforto ambiental do citadino sempre esteve ligada a ambientes sombreados pelas árvores dos generosos quintais que ponteavam toda a área urbana, por vezes cortados por pequenos córregos. Atualmente, devido à acelerada atividade imobiliária, a população sente, psicológica e fisicamente, a perda destes espaços, importantes reguladores do clima local.

O presente trabalho teve por objetivo avaliar os laços topofílicos dos visitantes do "Parque Mãe Bonifácia", lugar importante para a amenização climática da região, funcionando como ponto de lazer para a população, sendo o maior espaço destinado para este fim na cidade. A avaliação, realizada através de entrevistas, foi complementada por um estudo microclimático cujas informações foram utilizadas como suporte para uma discussão mais generalizada da relação da população com o Parque.

\section{MATERIAIS E MÉTODOS}

\section{Área de estudo}

A cidade de Cuiabá deve sua origem à exploração do ouro nos rios da região no ínicio do século XVIII, se constituindo a partir das lavras, criando um traçado sem plano com ruas estreitas e tortuosas. A localização no interior do continente deixou a cidade durante 
muito tempo a margem do movimento capitalista realizado sobre a vida urbana, acontecendo de forma acelerada e desorganizada somente a partir das décadas de 1960।70. Atualmente a cidade de Cuiabá conta com aproximadamente 700 mil habitantes sendo um pólo das atividades econômicas da região através de suas indústrias e comércio.

A macrozona urbana da cidade de Cuiabá, MT, com $252 \mathrm{~km}^{2}$, localizada no Centro Geodésico da América do Sul, está situada na zona intertropical do Planeta, com clima do tipo Aw, segundo a classificação de Köppen, identificado prioritariamente pela temperatura, apresentando duas estações bem definidas, uma seca, de abril a outubro, e outra chuvosa, de novembro a março, com médias entre $28^{\circ} \mathrm{C}$ e $32{ }^{\circ} \mathrm{C}$.

A pluviosidade média anual fica em torno de $1500 \mathrm{~mm}$, concentrada na estação chuvosa. A concentração das chuvas produz na região grandes contrastes ao longo do ano nas superfícies vegetadas, apresentando nos períodos de secas, alto risco de queimadas, favorecendo uma modificação periódica espacial e temporal no albedo e na umidade do solo e, conseqüentemente, na variabilidade dos processos físicos da atmosfera da região. A cobertura vegetal da área urbana é constituída por remanescentes de cerrado e matas ciliares, formando um verdadeiro cinturão em torno da área urbana de Cuiabá.

Como forma de se preservar uma grande área de cerrado preservado da zona urbana da cidade, lugar outrora ocupado por um quilombo, foi criado em 2000 o primeiro parque urbano do estado do Mato Grosso, o Parque da Cidade Mãe Bonifácia. Segundo a lenda da região, Mãe Bonifácia era uma velha negra que controlava a entrada dos escravos foragidos no quilombo.

A existência de uma grande área preservada do cerrado original na região central da cidade tem explicação no fato de que, a apartir da década de 1970, esta esteve sob a guarda do Exército Brasileiro, servindo como espaço de treinamento militar. O Parque ocupa uma área de 77 ha numa região de grande expansão de empreendimentos imobiliários resultado, em parte, pela existência do Parque (Figura 1). 


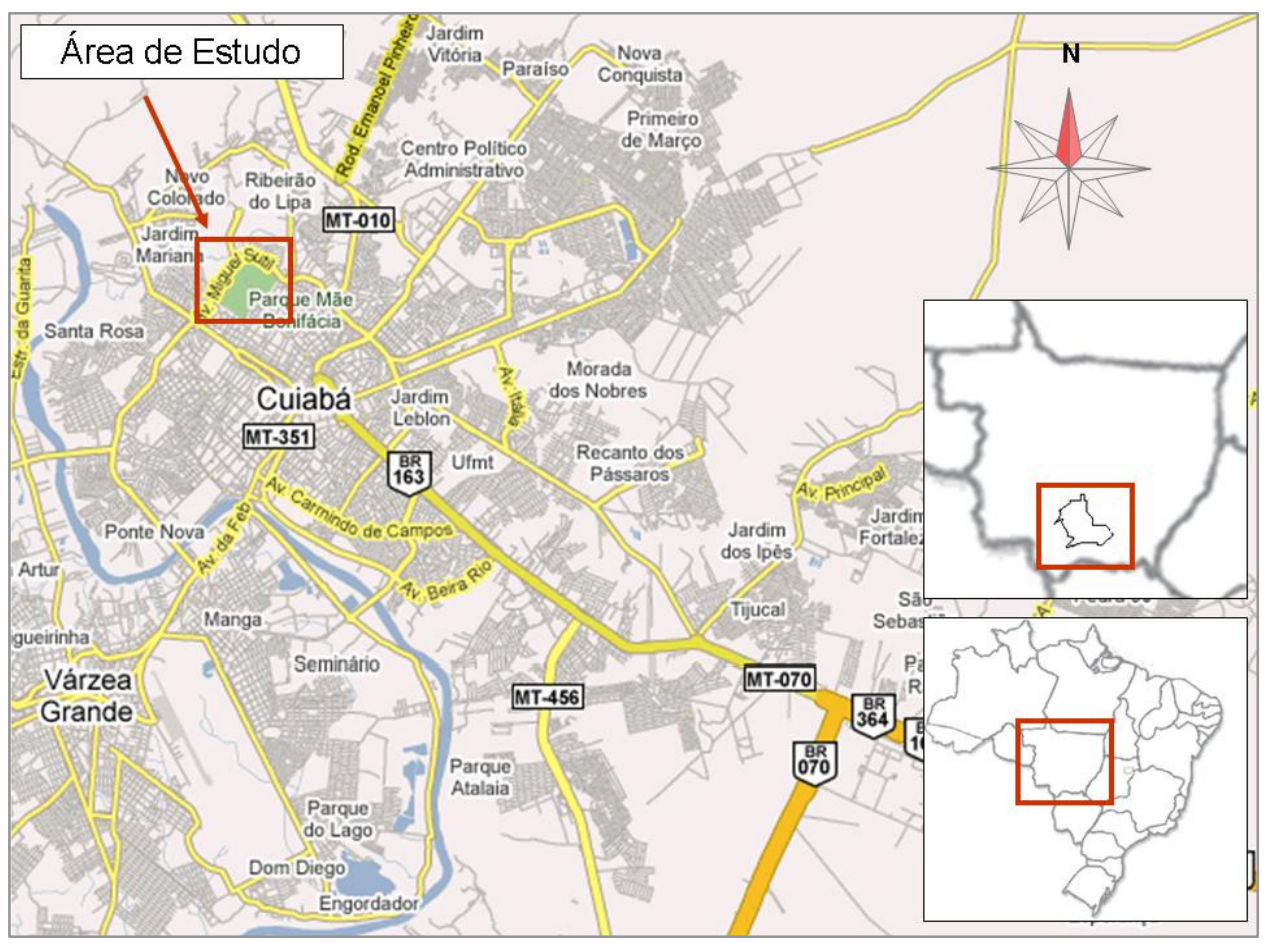

Figura 1 - Localização da área de estudo

Fonte: Google Maps, 2008

A cobertura vegetal do Parque é formada por mata ciliar e cerrado, servindo de abrigo a diversas espécies da fauna silvestre. Além do córrego que lhe empresta o nome, o Parque é também cortado pelo córrego do Caixão, na divisa leste, formando uma grande área de alagamento na sua região central.

A infra-estrutura do Parque é constituída por cinco trilhas, pontos de convívio como a praça da bandeira, a praça cívica para a realização de eventos e o casarão para a educação ambiental, todos situados na porção central, e a praça do cerrado com brinquedos, equipamentos de ginástica, concha acústica, coreto, bebedouro, posto de atendimento médico e sanitários, na entrada principal do Parque (Figura 2). 


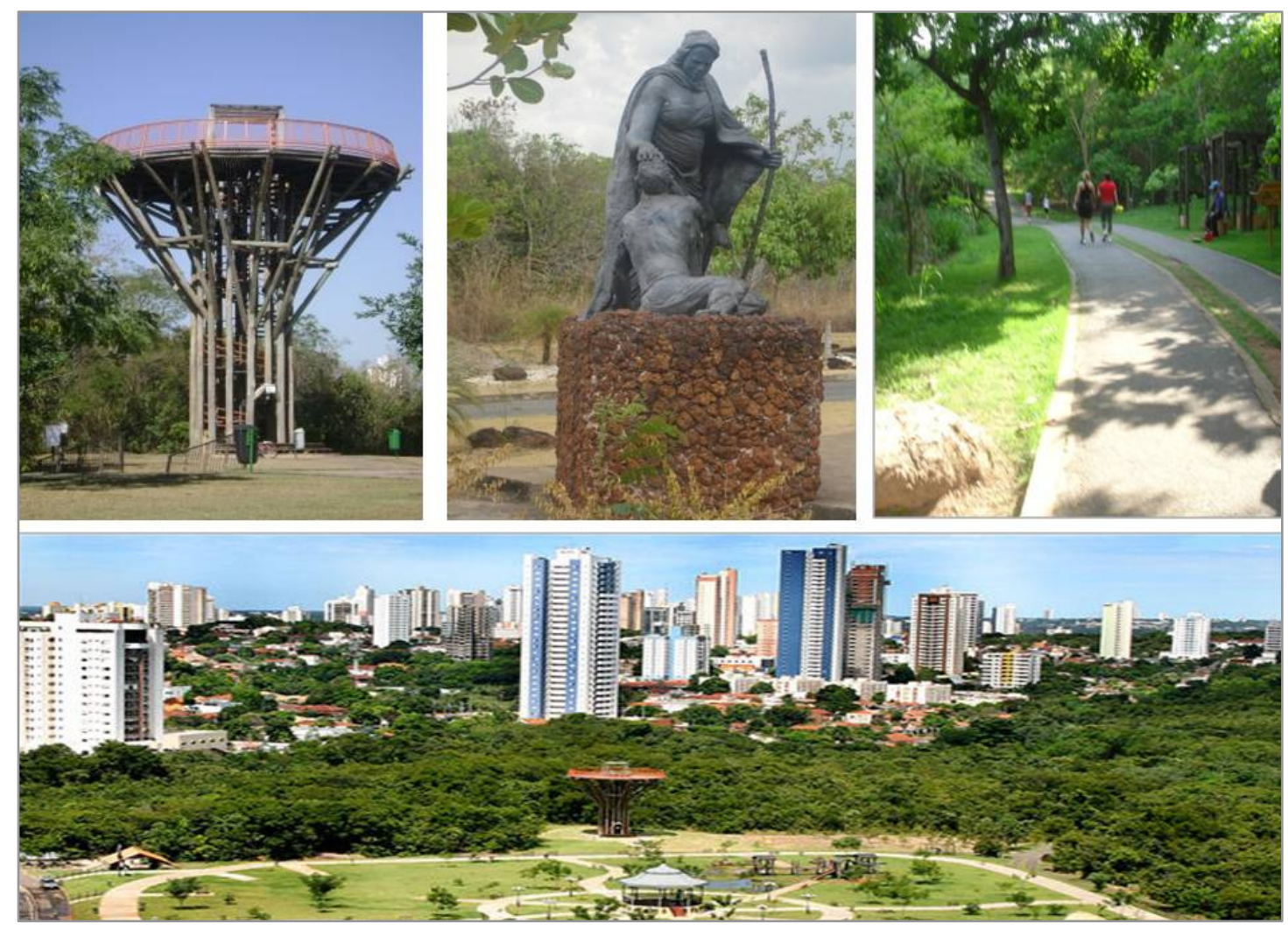

Figura 2 - Mirante, Estátua, Trilhas e Visão Superior do Parque Mãe Bonifácia.

\section{O ESTUDO TOPOFÍLICO}

Devido à carência de conhecimento acumulado e sistematizado sobre a percepção que os visitantes têm do Parque Mãe Bonifácia, optou-se pela elaboração de entrevistas semiestruturadas para a caracterização do sentimento topofílico dos visitantes para com o Parque. Inicialmente foi elaborado um pré-roteiro das entrevistas que, após discussões entre os integrantes da pesquisa, originou o roteiro definitivo, mais claro e objetivo, evitando frases longas e expressões técnicas.

O roteiro definitivo da coleta de dados foi elaborado com 4 questões abertas que, associadas à frequência semanal com que o entrevistado visita o parque, procurou avaliar a imagem do Parque, explorando o sentimento topofílico em relação ao mesmo. O horário escolhido para as entrevistas e medições dos dados climáticos foi o período das $07 \mathrm{~h}$ até as $09 \mathrm{~h}$, quando se concentra o maior fluxo de visitantes pelos espaços do Parque.

A análise da percepção teve início com a identificação do público que frequenta o Parque através das variáveis, sexo, instrução e idade. Para a entrevista foram selecionados apenas indivíduos com idade superior a 18 anos, idade em que, segundo Piaget (1973), se concretiza a formação e a interpretação simbólica. 
As entrevistas foram realizadas na Praça do Cerrado, verificando sempre a faixa etária do entrevistado, que, de forma voluntária, era convidado a responder às questões, respeitando o direito de privacidade e garantindo que suas respostas não teriam outro fim senão a pesquisa. No caso de aceitar participar da pesquisa, os entrevistados eram esclarecidos da finalidade e da sua importância na participação da mesma. As entrevistas aconteceram nos meses de novembro e dezembro de 2007, no período chuvoso onde as temperaturas médias são mais elevadas.

Finalizada essa etapa, com a variedade de respostas obtidas foi realizada uma análise exploratória dos dados por estatística coesitiva, através do software CHIC (Classification Hiérarchique Implicative et Cohésitive) para uma análise implicativa de variáveis. Esse tipo de análise relaciona comportamentos e, para tanto, foi necessário um levantamento de variáveis pertinentes para o estudo, de acordo com as respostas obtidas para as questões da entrevista.

Posteriormente, com o software $\mathrm{CHIC}$, foi construído um gráfico implicativo entre variáveis levantadas no início do estudo. O resultado dessa análise forneceu subsídios necessários para avaliar os aspectos de percepção e topofilia dos visitantes com relação ao Parque.

\section{O estudo microclimático}

As coletas dos dados microclimáticos foram realizadas em paralelo às entrevistas, em dias característicos da estação. Foram utilizadas para tanto estações digitais portáteis com data-logger modelo TGD-300 do fabricante Instrutherm e medidores multifunção ITMP600 da Instrutemp todos devidamente calibrados e sincronizados.

Nos dias de entrevistas as estações digitais portáteis foram instaladas na entrada do Parque (Estação 2), nas trilhas internas (Estação 1), e em um Posto de Controle em um ponto externo ao Parque (Estação 3), locado em uma ilha de calor detectada próxima a região central da cidade (MAITELLI, 1994). As estações foram instaladas 30 minutos antes do início dos trabalhos, a 1,5 m do solo e devidamente protegidas da radiação solar direta.

A caracterização do ambiente térmico do lugar foi realizada através de um mapa de temperaturas, confeccionados por krigagem ordinária, utilizando para tanto os dados coletados em um dia característico do período de medições. A análise exploratória dos dados e a geoestatística elaborada foram realizadas pelos softwares Surfer ${ }^{\circledR}$ versão 8.01 e Gamma Design versão 5.0.3. 


\section{RESULTADOS E DISCUSSÃO}

\section{Caracterização do público que freqüenta o parque}

A população entrevistada foi classificada em três faixas etárias, de 18 a 24 anos, 25 a 49 anos e acima de 50 anos, e três faixas de diferentes níveis de escolaridade, ensinos fundamental, médio e superior concluídos. A classificação, além de permitir uma identificação do público que frequenta o Parque, foi necessária para uma melhor compreensão dos fenômenos perceptivos estudados, conciliados com os objetivos propostos, uma vez que a percepção de um ambiente varia significativamente entre homens e mulheres e entre indivíduos com escolaridades e idades diferentes.

A maior parte dos entrevistados tem entre 25 e 49 anos, devem estar em pleno gozo de sua vida profissional e ser economicamente ativos. Do total de entrevistados, $72 \%$ tiveram acesso à universidade, em uma maioria de homens, conforme mostram as Figuras 03, 04 e 05.

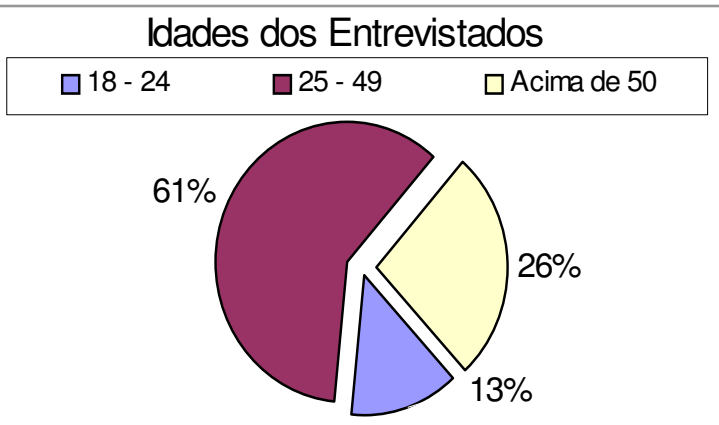

Figura 03 - Percentual de idade dos entrevistados

Fonte: Pesquisa dos autores (2007)

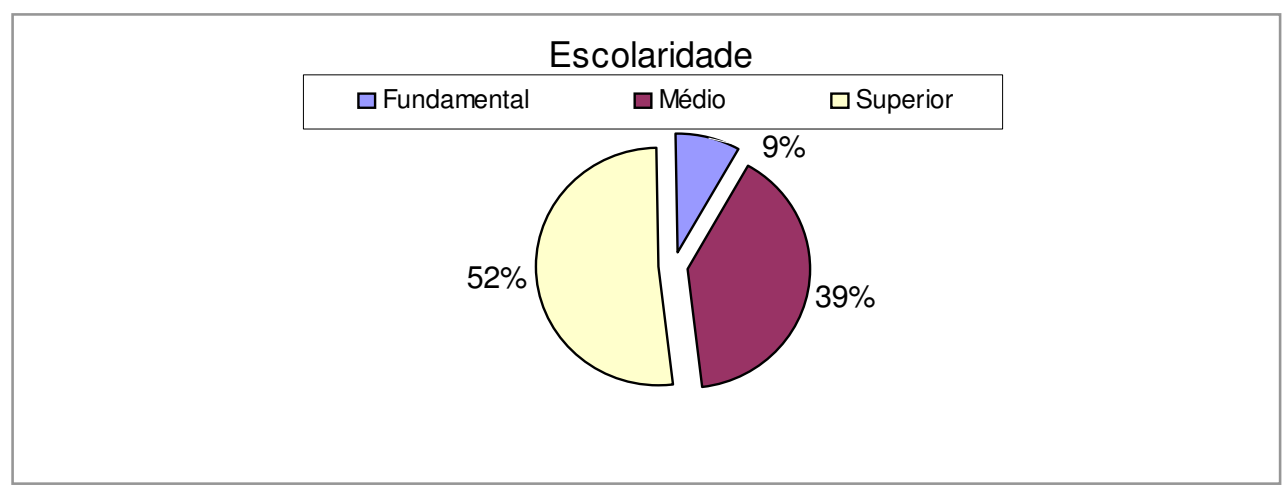

Figura 04 - Escolaridade dos entrevistados

Fnnte: Pesnuisa dns autores (2nก7) 


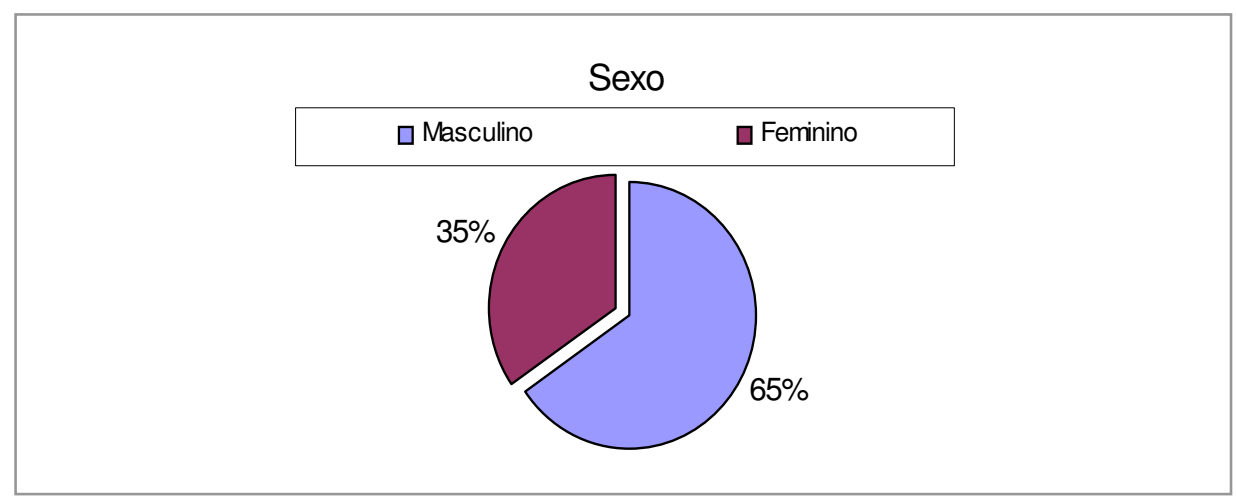

Figura 05 - Gênero dos entrevistados

Fonte: Pesnu issa dns autores (?nก7)

\section{Análise da percepção e imagem do parque para seus visitantes}

Para melhor caracterizar os resultados quanto às representações mentais do Parque, as respostas dos entrevistados nos quesitos imagem, motivos para visitação e pontos positivos foram classificadas em 10 categorias, conforme apresentadas na Tabela 01.

TABELA 01 - Categorias em que foram classificadas as respostas dos Entrevistados

\begin{tabular}{|l|l|}
\hline Categorias das Respostas & Respostas Mais Comuns \\
\hline V1. Bem-estar anímico & Calma, oásis e aconchegante. \\
V2. Bem-estar clínico & Saúde, arejado e exercícios físicos. \\
V3. Convívio social & Lugar para conversar e amizades. \\
V4. Empatia & Bonito, diferente e atrativo. \\
V5. Gestão & Limpeza, falta de segurança e horário de \\
V6. Identificação com a política regional & fechamento. \\
V7. Infra-estrutura & Falha na manutenção pelo governo. \\
V8. Localização & Falta de sanitários e iluminação. \\
V9. Meio ambiente & Dentro da cidade. \\
V10. Refúgio & Natureza e área verde. \\
\hline
\end{tabular}

Fonte: Pesquisa dos Autores, 2007

Assim classificadas as respostas, foi realizada através do software CHIC a análise de similaridade entre as respostas dos entrevistados. A aplicação de estatística coesitiva às 
categorias das respostas de cada usuário usando o método entrópico e a distribuição binomial produziu a árvore de similaridades de classes pequenas com, no máximo, três elementos, conforme a Figura 06. Isso foi provocado pelo grande número de variáveis em relação ao número de entrevistados.
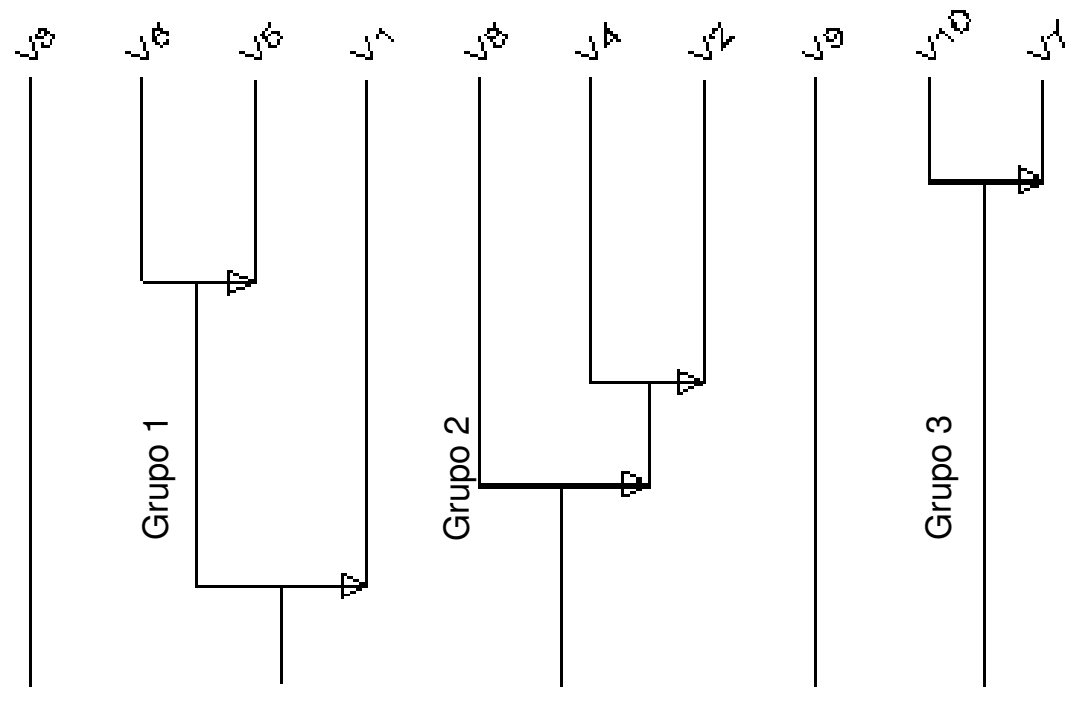

Figura 06 - Árvore de similaridades entre as categorias classificadas as $\mathrm{N}$ respostas dos entrevistados

o primeiro grupo existe uma forte correlação, muito fácil de ser explicada, entre as categorias V5 e V6, correspondentes à gestão e identificação com a política regional. Essas comparações, de modo geral, são feitas por pessoas que usam o espaço há muito tempo, talvez desde a fundação, e traçam comparativos entre os gestores do Estado de Mato Grosso e o nível de conservação e manutenção do Parque. Com menor similaridade, a análise permite inferir que o mesmo usuário relacionou às duas categorias anteriores, V5 e V6, ao bem-estar anímico, talvez relacionado ao descuido do gestor do espaço, observado por estes entrevistados, a alguns quesitos julgados como importantes para o bem-estar no espaço.

A relação entre empatia e bem-estar clínico é a tônica do segundo grupo, sendo difícil estabelecer a prioridade numa relação causal entre esses fatores. Nas referências citadas pelos entrevistados fizeram-se evidentes os julgamentos de valor correspondentes às percepções aprazíveis, fortes características do sentimento topofilico para com o lugar. Esse sentimento é reforçado pela categoria localização que, apresentando similaridade 
menor com a empatia e o bem-estar clínico, estabelecendo uma idéia de identidade, no sentido de localização dentro da cidade ou do bairro do entrevistado.

O último grupo apresenta a correlação de apenas dois fatores, refúgio e infraestrutura, porém, a mais forte entre as categorias analisadas. Os comentários classificados como refúgio permitem inferir que são visitantes integrados ao ambiente, que o percebem como seu lugar e que se sentem envolvidos pela natureza e pelo cenário.

A similaridade entre as duas categorias, refúgio e infraestrutura, sugere a percepção de um necessário cuidado aos equipamentos de uso público do Parque para garantir momentos aprazíveis com os familiares ou instantes de recolhimento no seu interior.

As categorias V3 e V9, convívio social e meio ambiente, são neutras, como se estivessem divididas entre todas as relações implicativas, compatíveis com o padrão de respostas observado nesta análise. A distribuição das representações em cada categoria é apresentada na Figura 07.

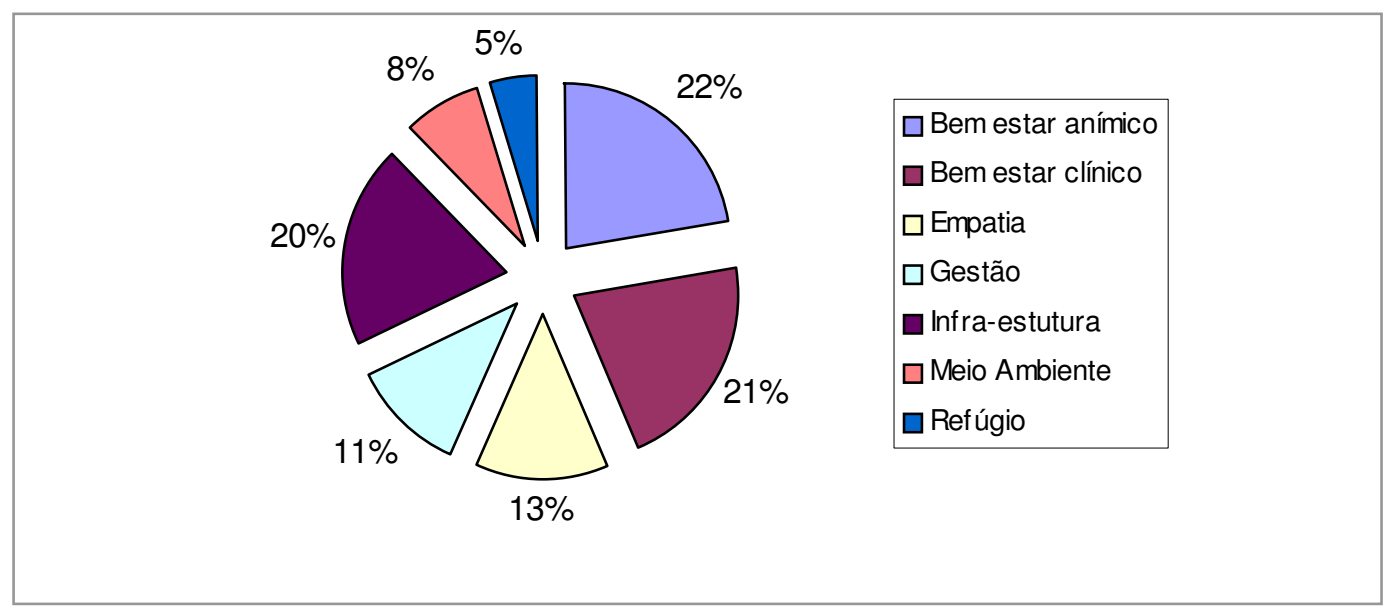

Figura 07 - Percepção do Parque para os entrevistados

Fonte: Pesquisa dos autores (2007)

Os julgamentos de valor e percepção, especialmente no que se refere à aprazibilidade do lugar, através das sensações de bem-estar e empatia para com o ambiente, apareceram com a mesma regularidade para homens e mulheres. Regularidade semelhante para os julgamentos de valor e percepção também foi verificada em relação à escolaridade e idade. 
$\mathrm{Na}$ questão estimulada que buscava levantar pontos negativos do Parque, a maior parte das reclamações foi em relação à manutenção, relacionada na categoria de gestão, e questões de infraestrutura, como carência de banheiros públicos, sinalização e segurança, conforme a Figura 08.

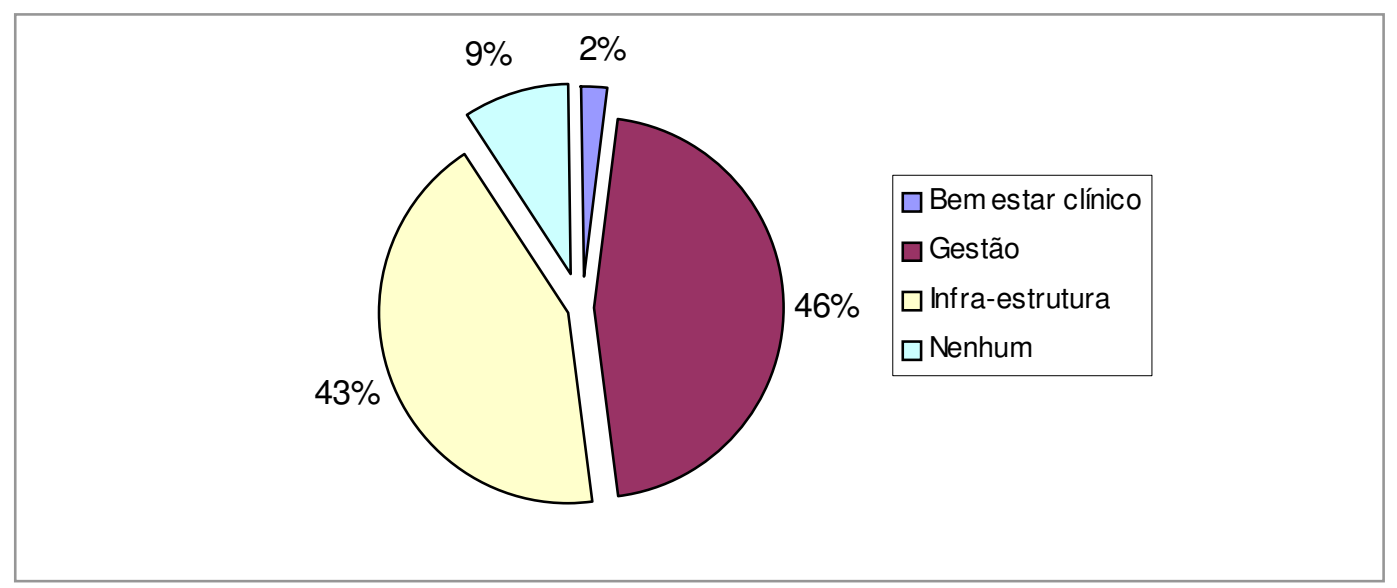

Figura 08 - Pontos negativos na percepção dos entrevistados

Fonte: Pesquisa dos autores (2007)

Um fator interessante de avaliação foi observar que $25 \%$ das respostas na categoria gestão fizeram referência à sensação de insegurança no interior do Parque, ao mesmo tempo em que uma percentagem um pouco maior dos entrevistados destacam a tranquilidade do lugar. A estrutura de segurança é constituída por três postos policiais, localizados nos estacionamentos das entradas e na administração central, onde pode ser encontrado o serviço de guarda do Parque. No interior do Parque o policiamento preventivo é realizado por policiais militares que percorrem as trilhas em bicicletas durante o dia. No período noturno o Parque é fechado para o público.

Em levantamento realizado pela Polícia Judiciária Civil, das principais ocorrências registradas na delegacia distrital responsável pela área que compreende os bairros da região centro-norte da cidade de Cuiabá, no período de 01 de janeiro a 30 de novembro de 2007, dos 103 casos registrados, 51 aconteceram no bairro Quilombo, no entanto nenhum foi registrado como ocorrido no interior do Parque (MATO GROSSO, 2007).

A avaliação da frequência com que os entrevistados visitam o Parque semanalmente revela que $61 \%$ o fazem com uma regularidade superior a 3 vezes por semana, conforme a Figura 09. 


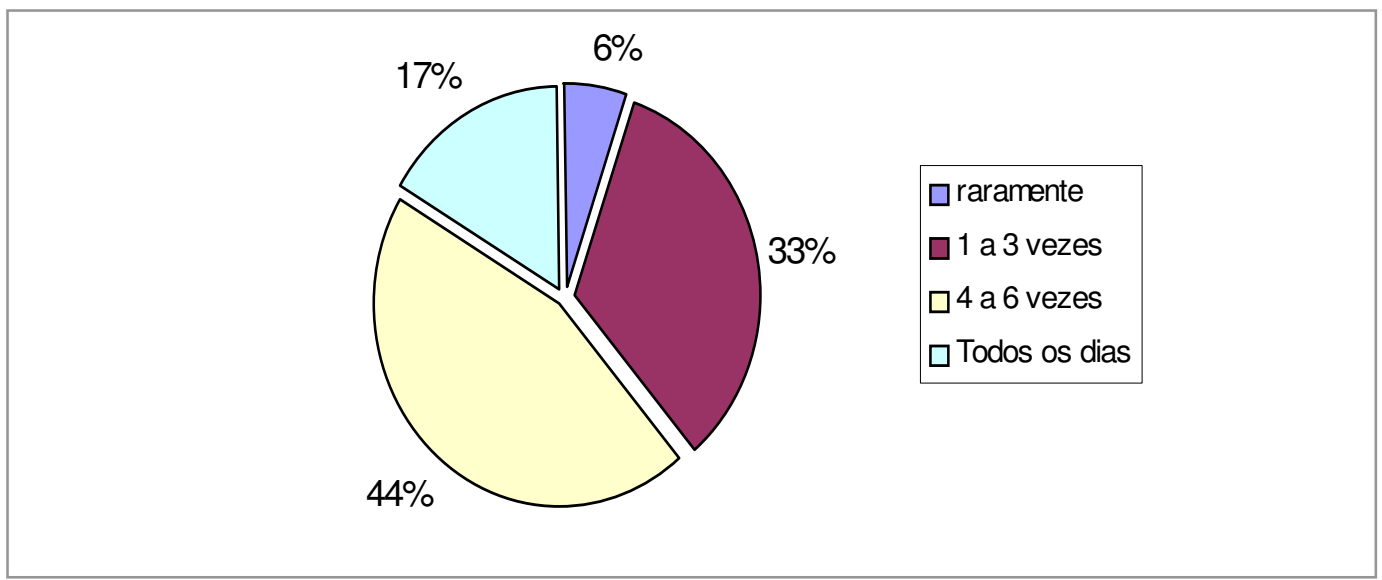

Figura 09 - Freqüência, ao longo da semana, com que os entrevistados visitam o Parque

Fonte: Pesquisa do autor (2007)

\section{Análise microclimática}

O estudo do ambiente climático do Parque Mãe Bonifácia permitiu demonstrar que a formação deste está diretamente associada aos padrões de ocupação do solo. Nos períodos de medições a temperatura do ar, relativa ao Posto de Controle (Estação 3), apresentou amenizações máximas da ordem de $5{ }^{\circ} \mathrm{C}$ em pontos internos do Parque (Estação 1) e da ordem de $3,5^{\circ} \mathrm{C}$ na entrada principal (Estação 2).

Os dados obtidos confirmam a afirmação de Mascaró (1996), de que a vegetação interfere na radiação solar, vento e umidade do ar. Segundo esse autor, em alguns grupos arbóreos a temperatura do ar pode chegar a ser $3^{\circ} \mathrm{C}$ a $4{ }^{\circ} \mathrm{C}$ menor que em áreas expostas à radiação solar, variando conforme a estratificação do ar e o porte da vegetação.

Os valores máximo e mínimo da umidade relativa do ar na Praça do Cerrado foram de $76,0 \%$ e $64,3 \%$, enquanto que nos ambientes internos do espaço foram encontrados valores de no máximo $96,8 \%$ e mínimo de $69,9 \%$. No mesmo período o Posto de Controle registrou $74,7 \%$ e $48,8 \%$, para, respectivamente, os valores máximo e mínimo da umidade relativa do ar. Os resultados também indicaram que nas trilhas que seguem o contorno da área alagada ou a margem dos córregos constituíram microclimas com umidade relativa do ar em média $12 \%$ acima das registradas no Posto de Controle. Os resultados reforçam o impacto do clima da região sobre os espaços do lugar, em especial nas horas mais quentes do dia.

Na Figura 10 são apresentados apenas os dados relativos à temperatura do ar. Os dados de umidade relativa serviram somente para embasar a análise e a discussão dos resultados do ambiente climático. 


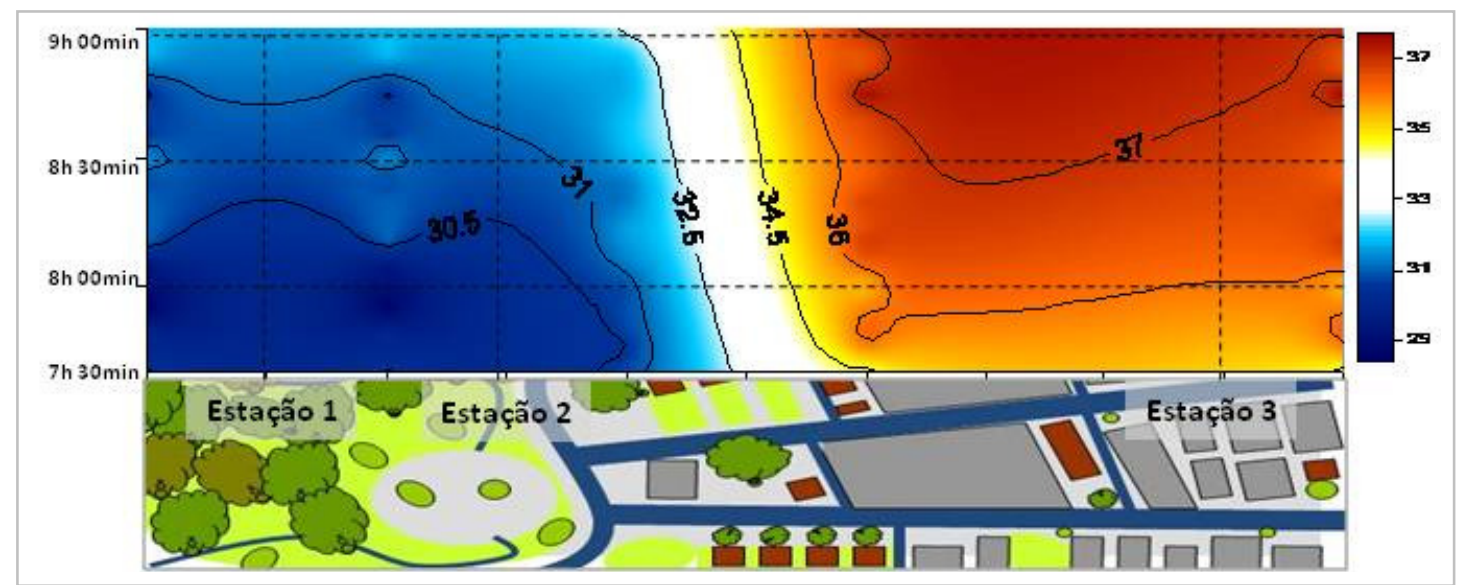

Figura 10 - Ilustração do ambiente térmico da região a partir da interpolação dos reaistros de temperatura do ar realizados no dia 07 de novembro de 2007.

Os resultados vieram a confirmar o Parque Mãe Bonifácia como uma llha de Frescor para a região sendo o seu ambiente térmico favorecido devido à configuração de suas construções que mantiveram o cerrado original da região, produzindo trilhas estreitas onde a copa das árvores que se encontram minimizam a entrada de radiação solar (Figura 11).
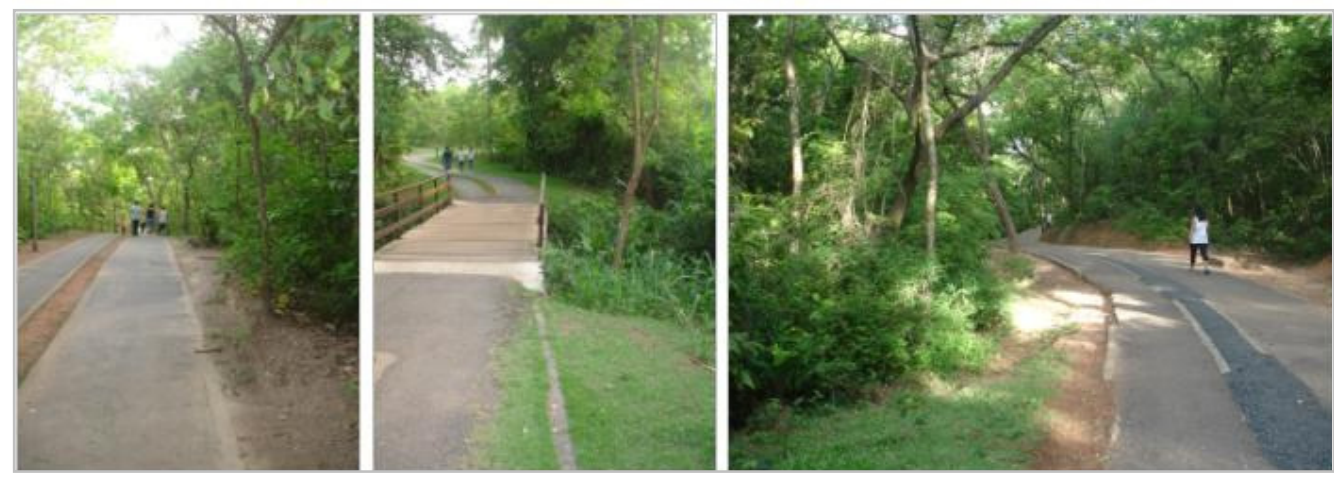

Figura 11 - Trilhas Internas do Parque

$\mathrm{Na}$ estação seca o constraste entre o ambiente térmico do Parque e de outros ambientes construídos da cidade se acentua. Nesta época a região registra índices de umidade relativa do ar inferiores a 30\%, logo nas primeiras horas da manhã (BARROS, 2009). A escala de referência para o nível de umidade, produzida pela Organização Mundial da Saúde (OMS), indica estado de atenção para números entre 20\% e 30\%.

Para regiões tropicais com baixa umidade do ar, a presença de lagos, córregos, ou espelhos d'água em espaços abertos podem alterar significativamente as variáveis termohigrométricas por um resfriamento evaporativo, contribuindo para que as pessoas possam gozar de conforto térmico nesses ambientes. 
Também importante destaque deve ser dado à proteção dos ambientes da radiação solar. Espaços destinados ao deleite da população, como praças ou parques urbanos em regiões de elevada temperatura do ar, são fortemente dependentes do projeto que, transformando o microclima local, pela sua configuração, pode levar a sensações de conforto ou desconforto térmico aos seus usuários. Ambientes projetados para as pessoas podem ser abandonados caso revelem ser desconfortáveis. Ainda assim, alguns empreendimentos que visam modificar a configuração urbana em regiões tropicais têm início com a retirada de toda a cobertura natural do terreno.

Segundo Corbella (2003), nos centros urbanos os edifícios, que cresceram em altura e em massa aumentando a inércia térmica, associados a uma maior quantidade de ruas asfaltadas, absorvem mais energia solar devolvendo com a mesma intensidade tal energia para o espaço próximo.

\section{CONCLUSÕES}

Pelo estudo da percepção dos visitantes com relação ao Parque, destacam-se a qualidade de vida, nos sentidos de bem-estar, anímico e clínico, as belezas naturais, a infraestrutura, a empatia e o meio ambiente como os elementos perceptivos mais importantes citados pela população.

A percepção do Parque como meio ambiente deve estar associada à amenização climática, à absorção dos sons dos carros e ao contraste entre a suavidade inerente à vegetação e à rigidez dos ambientes construídos, entre outras funções atribuídas à vegetação presente em um ambiente urbano, especialmente nas regiões tropicais. Essa percepção estabelece uma idéia de identidade para com o lugar e promove atitudes de envolvimento e expressões de afeição pelo lugar.

Os resultados da análise microclimática indicam que, nesses ambientes, mesmo em situações de registro de temperaturas e umidade relativa altas, as brisas suaves e a sombra, em um meio ambiente com árvores, podem propiciar uma sensação de conforto térmico e visual nos usuários desses espaços, mesmo que as condições estejam distantes das zonas de conforto térmico estabelecidas por diferentes técnicas de avaliação climática de ambientes.

A relatada sensação de insegurança no Parque pode ser determinada por outros fatores sociais além da ocorrência de crimes violentos, sendo que a oferta de serviços relacionados ao lazer e infraestrutura urbana, assim como a presença de policiamento ostensivo provoca diretamente a sensação de segurança da população. Espaços em que não se percebe a presença ostensiva de policiamento podem causar a seus usuários 
insegurança, da mesma forma que espaços policiados podem trazer a falsa sensação de segurança.

Houve uma certa regularidade na percepção do Parque pelos visitantes. Mesmo com diferentes motivações para fazer uso do espaço, a compreensão sobre seu papel psicológico e climático para a cidade de Cuiabá apareceu em destaque.

Os julgamentos de valor correspondentes às percepções aprazíveis, a idéia de identidade para com o lugar e até mesmo os pontos citados como negativos do Parque, mas que fazem referência à conservação do espaço e à construção de novos pontos de apoio ao visitante, caracterizam uma definição de topofilia, ou seja, os indivíduos têm objetivos comuns e expressam sentimentos de afeição para com o lugar. Este sentimento resulta em atitudes de respeito, de preservação e conservação deste espaço, além de tornar possível o seu uso para programas de Educação Ambiental.

A afeição do visitante pelo Parque ficou evidenciada, mesmo que implicitamente, pela elevada frequência de visitas dos entrevistados ao Parque, o que nos forneceu indícios de uma empatia dos entrevistados para com o lugar, que os encanta e desperta neles o desejo de sempre visitá-lo.

\section{REFERÊNCIAS BIBLIOGRÁFICAS}

BARROS, M. P. Estudo Microclimático e Topofílico no Parque Mãe Bonifácia da Cidade de Cuiabá - MT. Cuiabá, 2009. 147 f. Dissertação (Mestrado em Física Ambiental) - Instituto de Física, Universidade Federal de Mato Grosso.

CORBELLA, O. Em Busca de uma Arquitetura Sustentável para os Trópicos - Conforto Ambiental. Rio de Janeiro: Editora Revan, 2003.

\section{MAITELLI, G. T. Uma Abordagem Tridimensional do Clima Urbano em Área Tropical} Continental: o exemplo de Cuiabá/MT. Tese (Doutorado em Climatologia) - USP, São Paulo, SP, 1994.

MASCARÓ, L. R. Ambiência Urbana. Porto Alegre: Sagra -D.C. Luzzatto, 1996.

MATO GROSSO. Secretaria de Justiça e Segurança Pública. Polícia Judiciária Civil. Principais Ocorrências Registradas no Entorno do Parque Mãe Bonifácia no Período de 01/10 à 30/11/2007. Cuiabá: SEJUSP, 2007. 
MENDONÇA, F. Clima e Planejamento Urbano em Londrina. In: Monteiro C. A. F.; Mendonça F. organizadores. Clima Urbano. São Paulo: Editora Contexto, 2003.

PIAGET, J. Seis Estudos em Psicologia. Rio de Janeiro: Editora Forense, 1973.

SANTOS, M. Da Totalidade ao Lugar. São Paulo: Editora da Universidade de São Paulo, 2005.

SARAMAGO, J. Ensaio Sobre a Cegueira. São Paulo: Companhia das Letras, 1995.

TUAN, Y. F. Topofilia - Um Estudo da Percepção, Atitudes e Valores do Meio Ambiente. São Paulo: Editora Difel, 1980.

WEIHE, W. H. La Esperanza de Vida en los Climas Tropicales en Función de la Urbanización. In: Organizacion Meteorologica Mundial. Conferencia tecnica sobre climatologia urbana y sus aplicaciones con especial referencia a las zonas tropicales in México. Geneva, 1986.

WORLD HEALTH ORGANIZATION - WHO; UNITED NATIONS ENVIRONMENT PROGRAMME - UNEP. Indoor Environment: Health aspects of air quality, thermal environment, light and noise. Geneva, 1990. 